\title{
THE AORTIC ROOT IN SUPRAVALVULAR AORTIC STENOSIS: THE POTENTIAL SURGICAL RELEVANCE OF MORPHOLOGIC FINDINGS
}

Christof Stamm, MD

Jia Li, MD

Siew Yen Ho, PhD, FRCPath

Andrew N. Redington, MD, FRCP

Robert H. Anderson, MD, FRCPath
Objective: We aimed to elucidate the structural basis of supravalvular aortic stenosis in the context of its surgical repair. Methods: We examined retrospectively the angiograms and echocardiograms of 37 patients and compared them with those of control groups. Additionally, we studied 8 pathologic specimens. Results: Partial adhesion of the leaflets to the stenosing ridge was observed in $54 \%$ of the cases and the leaflets were thickened and less mobile in 30\%. Forty-five percent of the angiograms showed evidence of coronary orificial stenosis. The sinuses of Valsalva were significantly enlarged in $\mathbf{7 5 \%}$ of the cases. Changes in dimensions of the aortic root were demonstrated more clearly by angiography than by echocardiography. In all anatomic specimens, a marked redundancy of the leaflets was observed and quantified. Conclusions: Our data demonstrate that the entire valvular apparatus is always affected by the so-called supravalvular stenosis. Anatomic restoration of the aortic root should ideally take into account all of the deformed components by enlarging all three sinuses of Valsalva at the sinotubular junction. (J Thorac Cardiovasc Surg 1997;114:16-24)
$\mathrm{C}_{\mathrm{a}}^{\mathrm{o}}$ ongenital supravalvular aortic stenosis occurs as a major feature of the Williams syndrome, as part of a dominantly inherited familial arteriopathy, or as an isolated defect in individual patients. Although the entity was first described by Chevers ${ }^{1}$ in 1842, it received relatively little attention for more than the following hundred years. ${ }^{2}$ The report of Denie and Verheugt ${ }^{3}$ in 1958 was the first of a series of detailed morphologic descriptions, ${ }^{4,5}$ which payed attention mainly to the so-called supravalvular manifestation of what is today known as a

From the Section of Pediatrics, National Heart and Lung Institute, Imperial College School of Medicine, London, United Kingdom.

Supported by a grant from the German Scientific Association to Dr. Stamm, who was a visiting fellow from the Department of Thoracic and Cardiovascular Surgery, University of Göttingen, Germany, during this investigation. Drs. Ho and Anderson are supported by the British Heart Foundation and the Joseph Levy Foundation.

Received for publication Oct. 21, 1996; revisions requested Jan. 2, 1997; revisions received Feb. 5, 1997; accepted for publication Feb. 10, 1997.

Address for reprints: R. H. Anderson, MD, FRCPath, Pediatrics, National Heart and Lung Institute, Imperial College School of Medicine, Dovehouse St., London SW3 6LY, United Kingdom.

Copyright (C) 1997 by Mosby-Year Book, Inc.

$0022-5223 / 97 \$ 5.00+0 \quad \mathbf{1 2 / 1 / 8 1 1 2 3}$ generalized disease caused by a spontaneous or inherited mutation of the elastin gene. ${ }^{6}$ The stenosis can be localized at the level of the sinotubular junction or can be seen as a diffuse narrowing of the entire ascending aorta, ${ }^{7}$ involving all the major arterial vessels in certain patients. ${ }^{8}$

Since the first successful surgical relief of this condition was reported in $1961,{ }^{9}$ interest has increasingly focused on the influence of the supravalvular narrowing on the function of the aortic valve itself. Abnormalities of the valvular leaflets are said to be found in $30 \%$ to $45 \%$ of the cases seen at operation or necropsy. ${ }^{7,10-12}$ Despite the development of elegant surgical techniques aimed at an anatomic restoration of the entire aortic root, ${ }^{12-15}$ the original simple patch enlargement of the sinotubular junction and the noncoronary sinus of Valsalva remains the standard treatment in many centers. $^{16-18}$ The need for more extensive operations remains a matter of controversy. To explore more fully the pathologic substrate, and hoping to add to the evidence in the debate concerning optimal surgical repair, we studied the echocardiograms and angiograms of 37 patients. We then correlated our observations with the pathologic findings in 8 anatomic specimens, assessing specifically the influence of the supravalvular narrowing on the proximal aortic structures. 

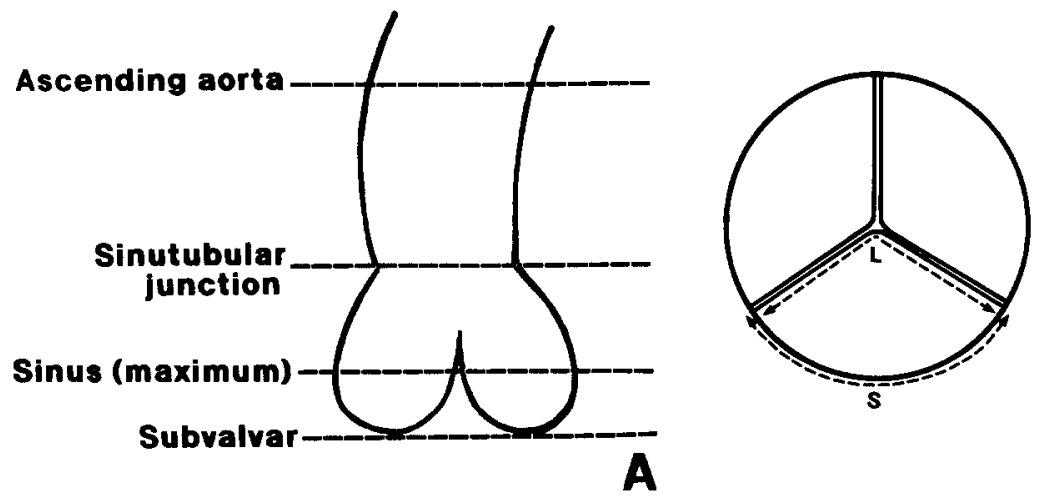

B

Fig. 1. A, Levels of measurements of aortic root diameters made on echocardiograms and angiograms. B, Measurements of the free edge of the aortic valvular leaflets $(L)$ and the corresponding part of the aortic wall at the highest level of insertion of the hinge points $(S)$.

\section{Patients and methods}

So-called supravalvular aortic stenosis was diagnosed in 37 patients at the Royal Brompton Hospital between 1990 and 1996. Of these patients, $22(59 \%)$ were male and 15 $(41 \%)$ were female; their ages at the time of presentation ranged from 1 month to 17 years (mean $4.6 \pm 4.1$ years). The majority $(73 \%)$ of the patients had no symptoms, whereas $8(22 \%)$ showed signs of heart failure and $2(5 \%)$ had a history of one or more syncopal episodes. Two deaths occurred during cardiac catheterization. Ten patients subsequently underwent surgical repair. Williams syndrome was present in $16(43 \%)$ of the patients, 11 $(30 \%)$ had a family history of nonsyndromic stenosis, and $10(27 \%)$ cases represented sporadic forms of the disease. Peripheral pulmonary stenosis was observed in $22(59 \%)$ of the patients. Other cardiovascular anomalies, excluding aortic valvular and coronary arterial malformations, were found in 9 patients (24\%): aortic coarctation in 2, pulmonary valvular stenosis in 3 , hypertrophic obstructive cardiomyopathy in 2, and atrial septal defect and mitral valvular prolapse in 1 each.

Specimens. The eight formalin-fixed anatomic specimens are part of the pathologic collection of the National Heart and Lung Institute, London. Age at the time of death ranged between 3 months and 26 years (mean 6.3 years). One of the specimen donors was known to have Williams syndrome and one had a proven family history of nonsyndromic stenosis; two cases were classified as sporadic discrete stenosis and four as sporadically occurring diffuse "macaroni-like" arteriopathy. ${ }^{8}$ Associated cardiovascular malformations included, each present in one heart only, pulmonary valvular stenosis, presence of bilateral superior caval veins, deficiency of the oval fossa, atrioventricular septal defect, and mitral valvular incompetence leading to valvular replacement.

Methods. For each patient, we reviewed the recorded cross-sectional and pulsed Doppler echocardiograms. Echocardiograms that provided satisfactory visualization of both the structures of the aortic root and the descending thoracic aorta and deemed suitable for further review were available from 30 patients. As a control group, echocardiograms of 20 patients without any cardiovascu- lar abnormalities, but a similar distribution of age (1 month to 15 years, mean $5.1 \pm 4.2$ years), were studied in the same fashion by an independent examiner. In the high parasternal long-axis view, we measured the diameters of the poststenotic ascending aorta, the sinotubular junction, the broadest width of the sinus of Valsalva, and the left ventricular outflow tract just below the basal attachments of the valvular hinge points (Fig. $1, A$ ). We also measured the diameter of the descending aorta and studied carefully the aortic valvular leaflets. For normalization of the data, the measurements of the aortic root in each patient were divided by the diameter of the descending aorta.

For 22 of the patients, angiographic recordings were available for retrospective evaluation. The same measurements as noted previously were taken from the posteroanterior projection, and the data processed as described. The anatomy of the coronary arteries and the mobility and thickness of the aortic valvular leaflets were carefully examined. Pressure gradients and evidence of valvular regurgitation were noted. Angiograms from 13 patients without any abnormalities of the left ventricular outflow tract or the aorta, but a similar range of age $(0.5$ to 16 years, mean $5.5 \pm 4.6$ years), were examined in the same way to give a control group.

In the anatomic specimens, we paid special attention to the structures of the aortic root and the ascending aorta. Because the descending aorta was not available for evaluation in every specimen, we were not able to normalize measurements of these structures as was possible with the echocardiograms and angiograms. The length of the free edge of each aortic valvular leaflet was measured, as was the internal wall of the aorta at the level of insertion of the hinge points at the sinotubular junction (Fig. 1, B). The ratio between these measurements was calculated to express the size of the leaflet in relation to its corresponding sinus. For comparison, the same measurements were performed in eight normal hearts. Further comparisons were made between the free edge of the leaflets and the corresponding circumference at the basal attachments of the valvular hinge points.

Statistics. Mean median and standard deviations were calculated. Shapiro-Wilk's W test was used to determine 
Table I. Anatomic types of stenosis in relation to clinical classification

\begin{tabular}{lccc}
\hline & Williams syndrome & Familial SVAS & Sporadic SVAS \\
\hline Hourglass & 9 & 9 & 5 \\
Tubular & 0 & 1 & 6 \\
\hline
\end{tabular}

SVAS, Supravalvular aortic stenosis.

the distribution of the data, the Mann-Whitney $U$ test to compare the abnormal data with those of control groups, and the Wilcoxon matched-pairs test to compare the data within one group.

\section{Results}

Gross morphology and hemodynamics. Echocardiographically, $23(77 \%)$ of the cases could be classified as showing discrete hourglass stenosis and $7(23 \%)$ as having diffuse tubular narrowing of the entire ascending aorta. No cases were encountered with a so-called diaphragmatic lesion. Angiography confirmed this classification for every examined case (17 [77\%] discrete and 5 [23\%] diffuse). In one patient, the diffuse aortic narrowing began $2 \mathrm{~cm}$ distal to the sinotubular junction, a finding documented echocardiographically and angiographically. In the remaining patients, the so-called supravalvular narrowing was found at the level of the anatomic sinotubular junction, with this again being demonstrated by both echocardiography and angiography. The distribution of the different anatomic types of the stenosis in relation to the clinical classification of the conditions is shown in Table I.

Pulsed Doppler echocardiography demonstrated a mean pressure gradient across the stenotic area of $65.8 \pm 29 \mathrm{~mm} \mathrm{Hg}$, ranging from 30 to $150 \mathrm{~mm} \mathrm{Hg}$. The mean pull-back gradient measured on catheterization of the left side of the heart was $42.4 \pm 23 \mathrm{~mm}$ $\mathrm{Hg}$ (range 15 to $95 \mathrm{~mm} \mathrm{Hg}$ ) and was significantly lower than the echocardiographically measured value in every patient $(p=0.004)$.

Aortic valvular abnormalities. Pulsed Doppler echocardiography revealed minimal to moderate aortic regurgitation in $6(20 \%)$ of the patients, whereas only minimal regurgitation could be demonstrated in $2(9 \%)$ of the cases examined angiographically.

A bicuspid aortic valve was not documented either by echocardiography (short-axis view) or by angiography, but 6 cases (27\%) showed the typical angiographic appearance of a "doming" aortic valve, a finding taken as evidence of valvular aortic stenosis. This was confirmed in each case by echocardi- ography, although the valvular element could not clearly be distinguished from the supravalvular component in any case.

The valvular leaflets were judged to be thickened in $9(30 \%)$ of the echocardiograms, with reduced mobility in $7(23 \%)$. Careful examination of angiograms revealed a similar incidence of thickened, less mobile leaflets $(n=6[27 \%])$. Partial adhesion of the free edge of a valvular leaflet to the supravalvular stenosing ring ${ }^{16}$ was observed at echocardiography in $9(30 \%)$ of the patients and involved 2 or all 3 of the leaflets. Angiography showed this feature in $12(54 \%)$ of the cases, but complete fusion of a valvular leaflet with the stenotic ring, thus excluding the corresponding sinus of Valsalva from the aortic blood flow, was never observed clinically.

Coronary arteries. arked dilation and tortuosity of one or both coronary arteries was observed angiographically in 5 cases (23\%). In all, the arterial orifices were within the sinus of Valsalva, well away from the sinotubular junction. In contrast, 10 cases (45\%) showed evidence of coronary arterial orificial stenosis involving one or both vessels at the level of or just below the sinotubular ridge. No cases, however, showed signs of myocardial compromise.

Aortic root dimensions. The average measurements compared with the corresponding control group measurements are presented as determined angiographically in Fig. 2 and echocardiographically in Fig. 3.

As determined by angiography, $17 \%$ of the patients showed a significantly wider subvalvular diameter, but none of the patients showed a significantly narrower subvalvular diameter. Echocardiography revealed a widened subvalvular diameter in $19 \%$ and a narrowed diameter in $10 \%$. The aortic diameter at the level of the sinuses of Valsalva was significantly enlarged in $75 \%$ of the angiograms and in $23 \%$ of the echocardiograms. In none of the patients was this dimension reduced. The sinotubular junction was narrowed significantly in all of the angiograms but in only $45 \%$ of the echocardiograms. In no case was it wider than in the control group. The ascending aorta was significantly narrowed in $37 \%$ of the angiograms but in none of the echocardiograms. It was widened significantly in $12 \%$ of the angiograms and $10 \%$ of the echocardiograms, all with hourglass stenosis. These percentages all represent the values that were more than two standard deviations greater or less than the average of the corresponding control group values (95\% confidence intervals). 


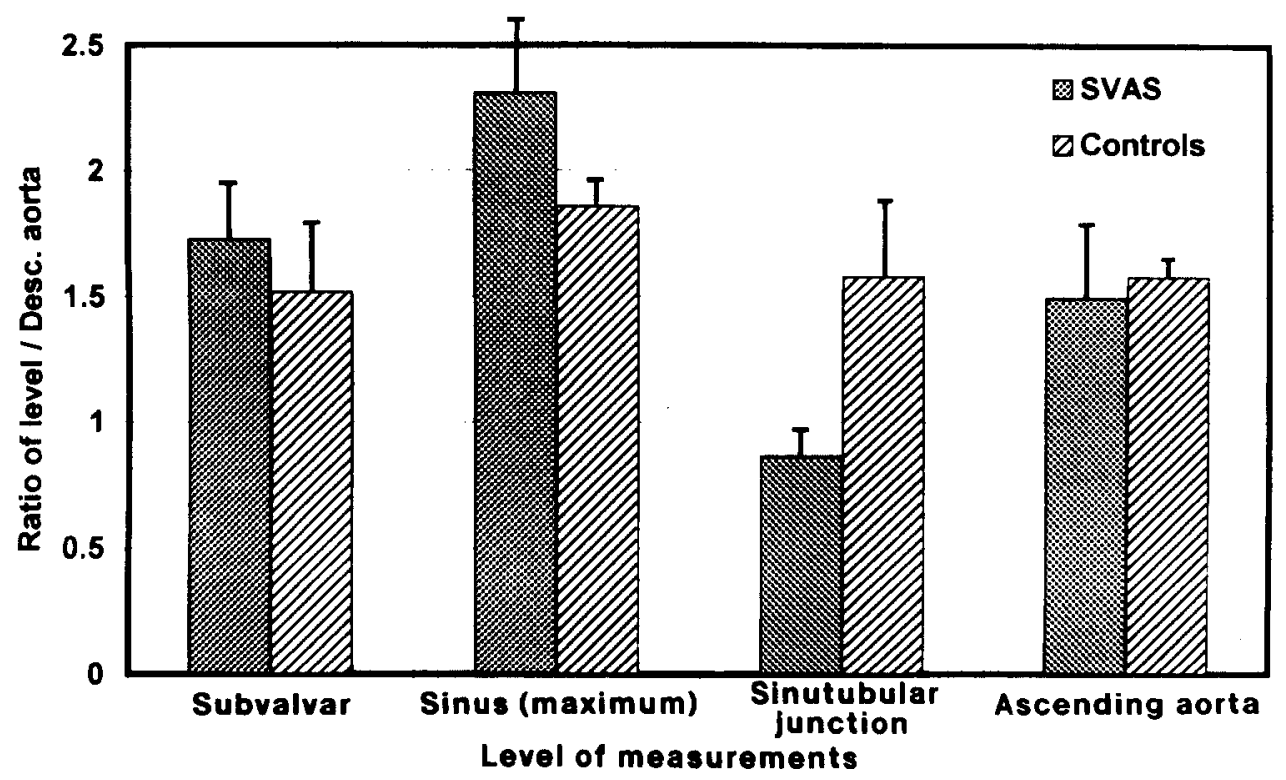

Fig. 2. Mean values of aortic root and ascending aortic diameters measured by angiography in patients with supravalvular aortic stenosis $(S V A S)(n=22)$ compared with values in the control group $(n=13)$, given as a ratio of the diameter of the descending (Desc.) aorta. Subvalvular, $p=0.005$; sinus, $p=0.0001$; sinotubular junction, $p<0.00001$; ascending aorta, $p=0.2$.

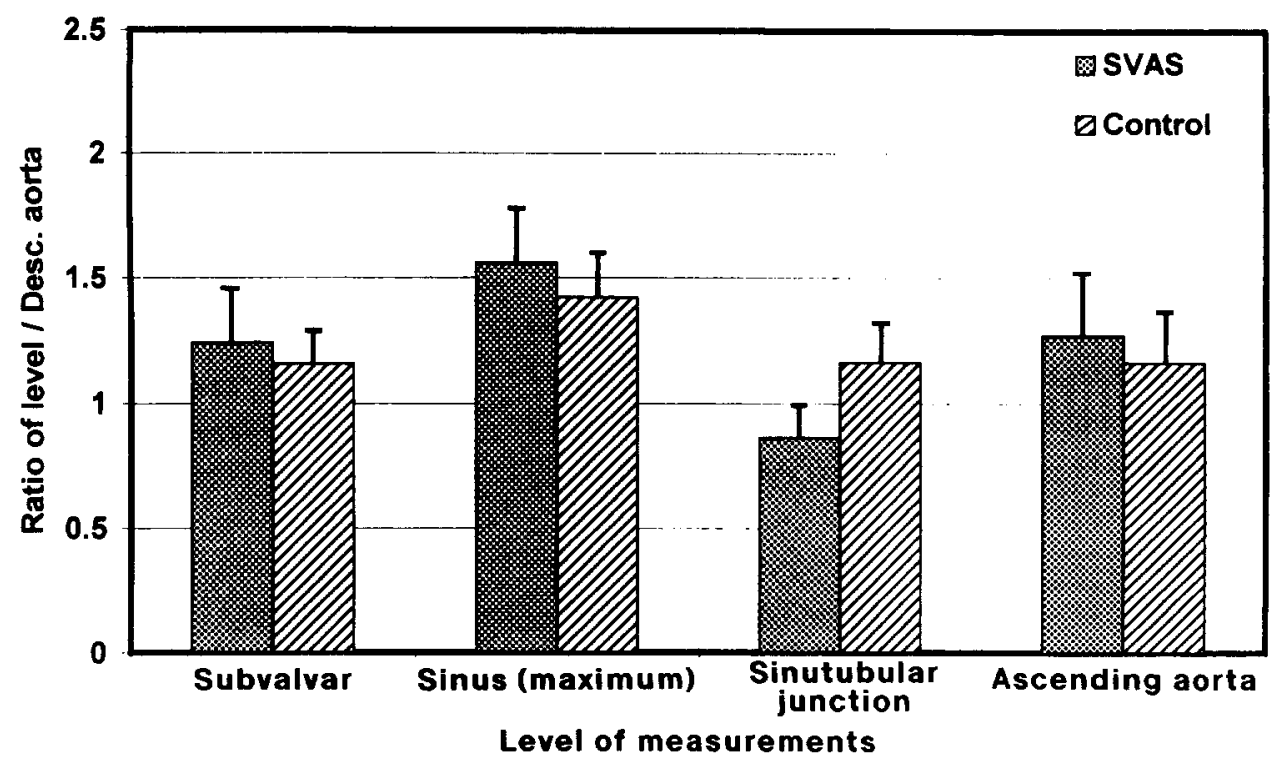

Fig. 3. Mean values of aortic root and ascending aortic diameters measured by echocardiography in patients with supravalvular aortic stenosis $(S V A S)(n=30)$ compared with values in the control group $(n=$ 20 ), given as a ratio of the diameter of the descending (Desc.) aorta. Subvalvular, $p=0.2$; sinus, $p=0.03$; sinotubular junction, $p=0.0001$; ascending aorta, $p=0.06$.

Anatomic specimens. The results of the pathologic examination of the heart specimens are given in Table II. The typical features of hourglass stenosis were present in three specimens (Fig. 4, a), and four hearts showed a tubular narrowing of the entire ascending aorta (Fig. 4, $b$ ). In the remaining heart, the stenosis took the form of a discrete membranous flap that encircled the aortic lumen at the level of 
Table II. Pathologic findings in heart specimens

\begin{tabular}{|c|c|c|c|c|c|c|}
\hline Specimen & Type & Leaflets & Sinuses & Sinotubular junction & Ascending aorta & Coronary orifice \\
\hline 1 & $\begin{array}{l}\text { Tubular, diffuse } \\
\text { arteriopathy }\end{array}$ & Thickened, redundant & $\begin{array}{l}\text { Thickened, } \\
\text { not dilated }\end{array}$ & $\begin{array}{l}\text { Thickened, } \\
\text { narrowed }\end{array}$ & $\begin{array}{l}\text { Thickened, } \\
\text { narrowed }\end{array}$ & Stenotic \\
\hline 2 & $\begin{array}{l}\text { Tubular, diffuse } \\
\text { arteriopathy }\end{array}$ & Delicate, redundant & $\begin{array}{l}\text { Thickened, } \\
\text { not dilated }\end{array}$ & Accentuated & $\begin{array}{l}\text { Thickened, } \\
\text { narrowed }\end{array}$ & Normal \\
\hline 3 & $\begin{array}{l}\text { Hourglass, diffuse } \\
\text { arteriopathy }\end{array}$ & $\begin{array}{l}\text { Thickened, redundant, } \\
\text { LC leaflet fused with } \\
\text { STJ }\end{array}$ & $\begin{array}{l}\text { RCS and NCS } \\
\text { dilated, LCS } \\
\text { isolated }\end{array}$ & $\begin{array}{l}\text { Thickened, } \\
\text { narrowed }\end{array}$ & $\begin{array}{l}\text { Thickened, } \\
\text { wide }\end{array}$ & $\begin{array}{l}\text { RCA } \\
\text { narrowed, } \\
\text { LCA } \\
\text { isolated } \\
\text { by fused } \\
\text { leaflet }\end{array}$ \\
\hline 4 & $\begin{array}{l}\text { Tubular, diffuse } \\
\text { arteriopathy }\end{array}$ & Delicate, redundant & $\begin{array}{l}\text { Thickened, } \\
\text { not dilated }\end{array}$ & $\begin{array}{l}\text { Thickened, } \\
\text { accentuated }\end{array}$ & $\begin{array}{l}\text { Thickened, } \\
\text { narrow }\end{array}$ & Normal \\
\hline 5 & Membranous & Normal, redundant & Normal & $\begin{array}{l}\text { Discretely } \\
\text { thickened }\end{array}$ & $\begin{array}{l}\text { Slightly } \\
\text { dilated }\end{array}$ & Normal \\
\hline 6 & Tubular & Thickened, redundant & $\begin{array}{l}\text { Thickened, } \\
\text { not dilated }\end{array}$ & $\begin{array}{l}\text { Thickened, } \\
\text { narrowed }\end{array}$ & $\begin{array}{l}\text { Thickened, } \\
\text { narrowed }\end{array}$ & Narrowed \\
\hline 7 & Hourglass & $\begin{array}{l}\text { Slightly thickened, } \\
\text { redundant }\end{array}$ & Dilated & $\begin{array}{l}\text { Thickened, } \\
\text { narrowed }\end{array}$ & Thickened, wide & Normal \\
\hline 8 & Hourglass & Delicate, redundant & Dilated & $\begin{array}{l}\text { Thickened, } \\
\text { narrowed }\end{array}$ & Normal & $\begin{array}{l}\text { LCA } \\
\text { stenotic, } \\
\text { RCA } \\
\text { dilated }\end{array}$ \\
\hline
\end{tabular}

$L C$, Left coronary; $L C A$, left coronary artery; $L C S$, left coronary sinus; $N C S$, noncoronary sinus; $R C A$, right coronary artery; $R C S$, right coronary sinus; $S T J$, sinotubular junction.

the sinotubular junction (Fig. 4, c). The aortic wall in this final heart was only minimally thickened, which distinguished this specimen from the other types of supravalvular stenosis. Irrespective of the type of stenosis, however, the ratio between the length of the free edge of the aortic leaflets and the corresponding part of the sinotubular junction, forming the upper margin of the aortic sinus, was significantly greater than that in the control group for every examined leaflet (Table III). When the ratio between the free edge of the leaflets and the circumference of the outflow tract measured at the basal extent of the valvular hinge points was calculated, however, there was no significant difference between the two groups (Table III).

\section{Discussion}

It is clear from our study that supravalvular aortic stenosis represents a developmental entity far more complex than the name implies. ${ }^{19}$ Whereas the first reports represented anecdotal findings in individual patients ${ }^{1-5}$ it was Williams, Barratt-Boyes, and Lowe, ${ }^{20}$ followed by Beuren, Apitz, and Harmjanz, ${ }^{21}$ who related this cardiovascular condition to a clinically recognizable syndrome. It has now been shown that this so-called supravalvular aortic narrowing is present to some degree in all patients with Williams syndrome $^{22}$ and in members of families affected by the autosomally dominant inherited variant. The lesion is also found in a number of patients without any syndromic or genetic history related to the condition. Genetic studies have now documented a defect of the elastin gene in patients with the syndromic disease. ${ }^{6}$ This deficiency produces ultrastructurally irregular elastic fibers, with secondary abnormalities in the distribution of collagen and smooth muscle cells in the aortic wall. ${ }^{5,23}$ The most common feature, nonetheless, is a thickening of the aortic media together with intimal hyperplasia, which not only results in an exaggeration of the anatomic sinotubular junction, but also involves all the major arteries, a feature shown elegantly with intravascular ultrasonography, as well as pathologically.

The historic descriptions given by Chevers ${ }^{1}$ and Mencarelli ${ }^{2}$ focused on the supravalvular narrowing of the aortic lumen as a structure separate from the aortic valve itself. Denie and Verheugt, ${ }^{3}$ in contrast, emphasized that the so-called supravalvular narrowing was located at the level of the insertion of the valvular hinge points at the sinotubular junction (the peripheral attachment of the valvular commissures). 

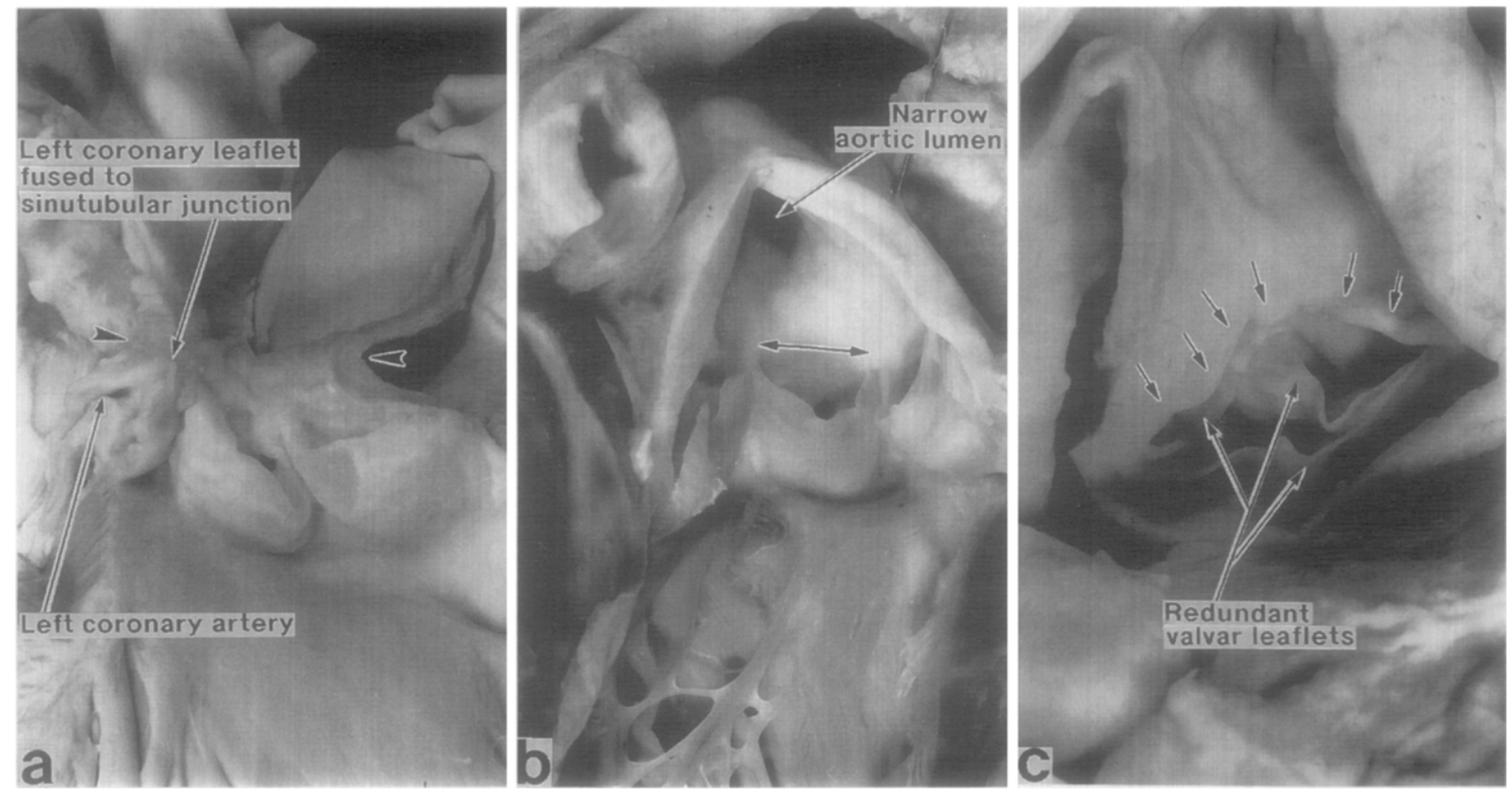

Fig. 4. a, Hourglass type of supravalvular aortic stenosis with a prominent waistlike appearance at the sinotubular junction (between arrowheads). The left coronary sinus and its leaflet have been sectioned longitudinally to show the isolation of the left coronary artery as a result of fusion of the leaflet to the arterial wall. Note the redundancy of the leaflets. b, Tubular type of supravalvular aortic stenosis. The aortic wall is thickened. The distance between the hinge points of the leaflets at the sinotubular junction (double arrows) is shortened, whereas the leaflets are markedly redundant. c, Diaphragmatic type of supravalvular aortic stenosis. A discrete membranous flap (arrows) at the sinotubular junction narrows the aortic lumen. The aortic wall is only minimally thickened. The valvular hinge points are drawn together, again leading to redundancy of the leaflets.

Morrow and coworkers ${ }^{4}$ then reported partial adhesion of the free edge of a thickened aortic valvular leaflet to the narrowing sinotubular ridge in one patient and the presence of elongated, saccular leaflets in another. McGoon and colleagues ${ }^{9}$ described the first successful relief of the stenosis by enlargement of the ascending aorta and the noncoronary sinus of Valsalva by insertion of a diamond-shaped patch. Doty, Polansky, and Jenson, ${ }^{12}$ Doty ${ }^{24}$ and Delius and colleagues ${ }^{25}$ then proposed a more symmetric enlargement of the aortic root by opening the noncoronary and the right coronary sinuses through insertion of a Y-shaped patch. Brom ${ }^{13}$ subsequently developed a technique to enlarge all three sinuses of Valsalva. Further modifications were described by Myers and associates ${ }^{14}$ and by Chard and Cartmill. ${ }^{15}$ Our anatomic findings justify the rationale of these more radical approaches to correction.

It is hardly surprising that a narrowed and rigid sinotubular junction, with its impact on the structure and function of the leaflets, leads to a variety of valvular abnormalities. Peterson, Todd, and Edwards ${ }^{7}$ documented involvement of the aortic valve in 13 of 43 cases examined anatomically when they reviewed the literature published by 1965 . Documented cases of severely thickened leaflets, partially or completely adherent to the narrowing sinotubular junction, have been described since. ${ }^{3,23,25}$ Surgical reports similarly describe frequent abnormalities of the leaflets: Rastelli and colleagues ${ }^{10}$ noted some degree of valvular disease in half of their patients, and an even higher percentage was observed by Keane and colleagues. ${ }^{11}$

Of particular importance is the marked mismatch between the length of the free edge of the leaflets and the corresponding part of the aortic wall at the sinotubular junction. This feature was noted by Doty, Polansky, and Jenson ${ }^{12}$ and Doty, ${ }^{24}$ but has not previously to our knowledge been quantified in anatomic specimens. Although the leaflets are redundant on account of the narrowed sinotubular 
Table III. Measurements of free edge of leaflet compared with parietal wall and circumference of subaortic outflow tract in heart specimens

\begin{tabular}{|c|c|c|c|c|c|c|c|c|}
\hline & \multicolumn{4}{|c|}{ Free edge/parietal sinus wall* } & \multicolumn{4}{|c|}{ Free edge/circ. of subaortic areat } \\
\hline & $N C$ & $R C$ & $L C$ & Mean & $N C$ & $R C$ & $L C$ & Mean \\
\hline \multicolumn{9}{|c|}{ SVAS hearts } \\
\hline 1 & 2.25 & 2.12 & 1.90 & & 1.19 & 1.16 & 1.18 & \\
\hline 2 & 1.60 & 1.67 & 1.70 & & 1.15 & 1.39 & 1.13 & \\
\hline 3 & 2.54 & 2.45 & 2.33 & & 2.00 & 1.35 & 1.26 & \\
\hline 4 & 1.80 & 1.67 & 1.80 & & 1.12 & 1.25 & 1.43 & \\
\hline 5 & 2.25 & 2.00 & 2.25 & & 1.00 & 1.22 & 0.94 & \\
\hline 6 & 2.17 & 2.40 & 2.40 & & 1.56 & 1.15 & 1.00 & \\
\hline 7 & 2.29 & 1.86 & 2.33 & & 1.67 & 1.45 & 1.67 & \\
\hline 8 & 1.54 & 2.00 & 2.33 & & 1.17 & 1.24 & 1.28 & \\
\hline Mean & 2.06 & 2.02 & 2.13 & 2.07 & 1.36 & 1.28 & 1.24 & 1.29 \\
\hline $\mathrm{SD}$ & 0.36 & 0.30 & 0.28 & 0.30 & 0.35 & 0.11 & 0.23 & 0.24 \\
\hline \multicolumn{9}{|c|}{ Control hearts } \\
\hline 1 & 0.94 & 1.07 & 1.13 & & 1.17 & 1.18 & 1.27 & \\
\hline 2 & 1.19 & 1.20 & 1.15 & & 1.23 & 1.55 & 1.27 & \\
\hline 3 & 1.04 & 1.16 & 1.11 & & 1.18 & 1.20 & 1.25 & \\
\hline 4 & 0.76 & 1.09 & 1.14 & & 1.13 & 1.12 & 1.42 & \\
\hline 5 & 1.17 & 1.10 & 1.07 & & 1.33 & 1.23 & 1.00 & \\
\hline 6 & 1.12 & 1.14 & 1.13 & & 1.33 & 1.43 & 1.22 & \\
\hline 7 & 1.18 & 1.33 & 1.20 & & 1.38 & 1.32 & 1.33 & \\
\hline 8 & 1.00 & 1.10 & 1.09 & & 1.33 & 1.15 & 1.18 & \\
\hline Mean & 1.05 & 1.15 & 1.13 & 1.11 & 1.26 & 1.27 & 1.24 & 1.26 \\
\hline SD & 0.15 & 0.08 & 0.04 & 0.11 & 0.09 & 0.15 & 0.12 & 0.12 \\
\hline
\end{tabular}

circ, Circumference, $L C$, left coronary leaflet/sinus; $N C$, noncoronary leaflet/sinus; $R C$, right coronary leaflet/sinus; $S D$, standard deviation; $S V A S$, supravalvular aortic stenosis.

*Difference between hearts with supravalvular aortic stenosis and control hearts, $p<0.00001$ by Mann-Whitney $\mathrm{U}$ test.

$\dagger$ Difference between hearts with supravalvular aortic stenosis and control hearts, $p=0.86$ by Mann-Whitney $\mathrm{U}$ test.

junction, their size is within the normal range when the free edge is compared with the circumference at the entrance to the subaortic outflow tract (the basal extent of the valvular hinge points). Brewer and colleagues, ${ }^{26}$ nonetheless, documented the systolic expansion of the aortic root, a process that leads to a certain straightening of the edges of the leaflets and maintenance of a more constant strain upon them, as a precondition for a limited fatigue stress on these rather delicate structures. A stiff and unexpandable sinotubular junction, together with a marked redundancy of the leaflets, does not permit this mechanism. Instead, it results in unlimited exposure of the valvular structures to the full forces occurring during the cardiac cycle. This promotes the premature degeneration of the leaflets seen as a feature in patients with so-called supravalvular stenosis, which is in reality stenosis at the level of attachment of the valvular leaflets to the sinotubular junction.

The sinotubular junction, therefore, represents an essential component of the aortic valvular appara- tus, morphologically and hemodynamically. Every pathologic process located at this level, obstructive or dilative, will sooner or later lead to compromise of valvular function. One must not be misled by the current nomenclature, which separates strictly the valvular and supposed "supravalvular" narrowing. What is called supravalvular aortic stenosis is functionally, and in many patients structurally, a disease of the entire aortic root. From the surgical standpoint, enlargement of one sinus with a single patch or two sinuses with an inverted $\mathrm{Y}$-shaped patch can certainly relieve the pressure gradient, as shown by extensive surgical experience. Complete anatomic restoration of the aortic root, in contrast, mandates interruption and enlargement of the narrowed sinotubular junction in all three sinuses of Valsalva.

Diagnostic considerations. It is recognized clinically that echocardiography in the nonsedated patient shows higher gradients across stenotic valves and vessels than are measured on catheterization, which in children is usually performed with the use of sedation or general anesthesia. This was noted for 
every case in which we compared the echocardiographic and angiographic findings. We also demonstrated a significant difference in quantification of the anatomic degree of pathologic changes in the aortic root. Angiography demonstrated a marked dilation at the level of the sinuses of Valsalva, whereas echocardiography underestimated the degree of sinusal dilation in the majority of patients. The degree of narrowing of the sinotubular junction was more marked when judged angiographically than when judged echocardiographically. For measurements of the left ventricular outflow tract and the ascending aorta, in contrast, the methods produced comparable results. Echocardiography is certainly more than capable of demonstrating the important diagnostic features of supravalvular aortic stenosis. ${ }^{27}$ Nevertheless, when assessment is done in the individual patient, it should be remembered that echocardiography tends to underestimate the changes in dimensions of the aortic root. These are as important for the evaluation of valvular function as the pressure gradient is for judging the effect on the left ventricular myocardium.

Coronary arteries. Coronary arterial abnormalities are a recognized feature of supravalvular aortic stenosis. ${ }^{7}$ Dilation or obstruction can occur in the proximal vessels, whereas structural changes of the arterial wall may be pressure-induced or part of the generalized arteriopathy. ${ }^{28}$ Various surgical techniques have been described for enlargement of the compromised arterial origin. ${ }^{15,29}$ In our patients, obstruction of a coronary orifice was more common than dilation and was usually found when the vessel arose very close to the thickened sinotubular ridge. This supports the findings of other groups, which previously emphasized the importance of coronary obstructive lesions coupled with the potential risk of sudden death.

Pathogenesis. Interestingly, it was the group with sporadically occurring stenosis that showed the highest incidence of the tubular form of aortic narrowing. All the cases with Williams syndrome were classified as hourglass-shaped stenosis. Because of the limited number of patients in each group, these findings lack statistical significance. Nonetheless, Wren, Oslizlok, and Bull ${ }^{30}$ also found exclusively discrete supravalvular stenosis in their group of patients with Williams syndrome. Although most authors consider the two forms simply as different degrees of the same disease, the accumulation of tubular stenosis in the group of nonWilliams and nonfamilial cases is striking. Further studies are needed to elucidate a possibly different pathomechanism in these patients.

Conclusions. Our study has provided strong anatomic evidence to support the initial contention of Denie and Verheugt ${ }^{3}$ that the so-called supravalvular stenosis is part and parcel of valvular stenosis. The nature of the circumferential narrowing at the sinotubular junction dictates that all three aortic sinuses require attention if ideal restoration of the aortic root is the goal of surgical correction.

\section{REFERENCES}

1. Chevers N. Observations on the discase of the orifice and valves of the aorta. Guys Hosp Rep 1842;7:387.

2. Mencarelli L. Stenosi sopravalvolare aortica ad anello. Arch Ital Anat Patol 1930;1:829-41.

3. Denie JJ, Verheugt AP. Supravalvular aortic stenosis. Circulation 1958;18:902-8.

4. Morrow AG, Waldhausen JA, Peters RL, Bloodwell RD, Braunwald E. Supravalvular aortic stenosis: clinical, hemodynamic and pathologic observations. Circulation 1959;20: 1003-10.

5. Perou ML. Congenital supravalvular aortic stenosis: morphological study with attempt at classification. Arch Pathol Lab Med 1961;71:453-66.

6. Keating MT. Genetic approaches to cardiovascular disease: supravalvular aortic stenosis, Williams syndrome, and long-QT syndrome. Circulation 1995;92:142-7.

7. Peterson TA, Todd DB, Edwards JE. Supravalvular aortic stenosis. J Thorac Cardiovasc Surg 1965;50:734-41.

8. McDonald AH, Gerlis LM, Somerville J. Familial arteriopathy with associated pulmonary and systemic arterial stenoses. Br Heart J 1969;31:375-85.

9. McGoon DC, Mankin HT, Vlad P, Kirklin JW. The surgical treatment of supravalvular aortic stenosis. J Thorac Cardiovasc Surg 1961;41:125-33.

10. Rastelli GC, McGoon DC, Ongley PA, Mankin HT, Kirklin JW. Surgical treatment of supravalvular aortic stenosis. J Thorac Cardiovasc Surg 1966;51:873-82.

11. Keane JF, Fellows KE, LaFarge CG, Nadas AS, Bernhard WF. The surgical management of discrete and diffuse supravalvar aortic stenosis. Circulation 1976;54:112-7.

12. Doty DB, Polansky DB, Jenson CB. Supravalvular aortic stenosis: repair by extended aortoplasty. J Thorac Cardiovasc Surg 1977;74:362-71.

13. Brom AG. Obstruction of the left ventricular outflow tract. In: Khonsari S, ed. Cardiac surgery: safeguards and pitfalls in operative technique. Rockville, Maryland: Aspen, 1988:27680 .

14. Myers JL, Waldhausen JA, Cyran SE, Gleason MM, Weber HS, Baylen BG. Results of surgical repair of congenital supravalvular aortic stenosis. J Thorac Cardiovase Surg 1993; 105:281-8

15. Chard RB, Cartmill TB. Localized supravalvar aortic stenosis: a new technique for repair. Ann Thorac Surg 1993;55: 782-4.

16. Flaker G, Teske D, Kilman J, Hosier D, Wooley C. Supravalvular aortic stenosis: a 20 -year clinical perspective with patch aortoplasty. Am J Cardiol 1983;51:256-60.

17. Sharma BK, Fujiwara H, Hallman GL, Ott DA, Reul GJ, 
Cooley DA. Supravalvar aortic stenosis: a 29 -year review of surgical experience. Ann Thorac Surg 1991;51:1031-9.

18. van Son JAM, Danielson GK, Puga FJ, et al. Supravalvular aortic stenosis: long-term results of surgical treatment. J Thorac Cardiovasc Surg 1994;107:103-15.

19. Blieden LC, Lucas RV, Carter JB, Miller K, Edwards JE. A developmental complex including supravalvular stenosis of the aorta and pulmonary trunk. Circulation 1974;49:585-90.

20. Williams JCP, Barratt-Boyes BG, Lowe JB. Supravalvular aortic stenosis. Circulation 1961;24:1311-8.

21. Beuren AJ, Apitz J, Harmjanz D. Supravalvular aortic stenosis in association with mental retardation and a certain facial appearance. Circulation 1962;26:1235-40.

22. Zalzstein E, Moes CAF, Musewe NN, Freedom RM. Spectrum of cardiovascular anomalies in Williams-Beuren syndrome. Pediatr Cardiol 1991;12:219-23.

23. O'Connor WN, Davis JB, Geissler R, Cottrill CM, Noonan JA, Todd EP. Supravalvular aortic stenosis: clinical and pathological observations in six patients. Arch Pathol Lab Med 1985;109:179-85.

24. Doty DB. Supravalvular aortic stenosis. Ann Thorac Surg 1991;51:886-7.
25. Delius RE, Steinberg JB, L'Ecuyer T, Doty DB, Behrendt DM. Long-term follow-up of extended aortoplasty for supravalvular aortic stenosis. J Thorac Cardiovasc Surg 1995; 109:155-63.

26. Brewer RJ, Deck D, Capati B, Nolan SP. The dynamic aortic root: its role in aortic valve function. J Thorac Cardiovasc Surg 1976;72:413-7.

27. Vogt J, Rupprath G, Grimm T, Beuren AJ. Qualitative and quantitative evaluation of supravalvular aortic stenosis by cross-sectional echocardiography: a report of 80 patients. Pediatr Cardiol 1982;3:13-7.

28. van Son JAM, Edwards WD, Danielson GK. Pathology of coronary arteries, myocardium, and great arteries in supravalvular aortic stenosis: report of five cases with implications for surgical treatment. J Thorac Cardiovasc Surg 1994;108:21-8.

29. Martin MM, Lemmer JH, Shaffer E, Dick M, Bove EL. Obstruction to left coronary artery blood flow secondary to obliteration of the coronary ostium in supravalvular aortic stenosis. Ann Thorac Surg 1988;45:16-20.

30. Wren C, Oslizlok P, Bull C. Natural history of supravalvular aortic stenosis and pulmonary artery stenosis. $\mathrm{J}$ Am Coll Cardiol 1990;15:1625-30.

\section{ON THE MOVE?}

Send us your new address at least six weeks ahead

Don't miss a single issue of the journal! To ensure prompt service when you change your address, please photocopy and complete the form below.

Please send your change of address notification at least six weeks before your move to ensure continued service. We regret we cannot guarantee replacement of issues missed due to late notification.

JOURNAL TITLE:

Fill in the title of the journal here.

OLD ADDRESS:

Affix the address label from a recent issue of the journal here.

\section{NEW ADDRESS:}

Clearly print your new address here.

Name

Address

City/State/ZIP

\section{COPY AND MAIL THIS FORM TO:} Journal Subscription Services Mosby-Year Book, Inc. 11830 Westline Industrial Dr. St. Louis, MO 63146-3318
OR FAX TO:

314-432-1158

N/ Mosby
OR PHONE:

1-800-453-4351

Outside the U.S., call

314-453-4351 